

\section{DISCLAIMER}

This report was prepared as an account of work sponsored by an agency of the United States Government. Neither the United States Government nor any agency thereof, nor any of their employees, make any warranty, express or implied, or assumes any legal liability or responsibility for the accuracy, completeness, or usefulness of any information, apparatus, product, or process disclosed, or represents that its use would not infringe privately owned rights. Reference herein to any specific commercial product, process, or service by trade name, trademark, manufacturer, or otherwise does not necessarily constitute or imply its endorsement, recommendation, or favoring by the United States Government or any agency thereof. The views and opinions of authors expressed herein do not necessarily state or reflect those of the United States Government or any agency thereof. 


\section{DISCLAIMER}

Portions of this document may be illegible in electronic image products. Images are produced from the best available original document. 


\title{
Low-Friction Coatings for Air Bearings in Fuel Cell Air Compressors
}

O. O. Ajayi, G. R. Fenske, A. Erdemir, J. Woodford, J. Sitts, K. Elshot, and K. Griffey

Argonne National Laboratory

Argonne, II 60439

\begin{abstract}
:
In an effort to reduce fuel consumption and emissions, hybrid vehicles incorporating fuel cell systems are being developed by automotive manufacturers, their suppliers, federal agencies (specifically, the U.S. Department of Energy) and national laboratories. The fuel cell system will require an air management subsystem that includes a compressor/expander. Certain components in the compressor will require innovative lubrication technology in order to reduce parasitic energy losses and improve their reliability and durability. One such component is the air bearing for air turbocompressors designed and fabricated by Meruit, Inc. Argonne National Laboratory recently developed a carbon-based coating with low friction and wear attributes; this near-frictionless-carbon (NFC) coating is a potential candidate for use in turbocompressor air bearings. We presents here an evaluation of the Argonne coating for air compressor thrust bearings. With two parallel $440 \mathrm{C}$ stainless steel discs in unidirectional sliding contact, the NFC reduced the frictional force four times and the wear rate by more than two orders of magnitude. Wear mechanism on the uncoated surface involved oxidation and production of iron oxide debris. Wear occurred on the coated surfaces primarily by a polishing mechanism.
\end{abstract}




\section{INTRODUCTION:}

To reduce petroleum-based fuel consumption and emissions from automotive vehicles, the U.S. Department of Energy (DOE) initiated a program to develop a protonexchange-membrane (PEM) fuel cell technology for transportation applications. This effort involves automotive,manufacturers, their suppliers, federal agencies, and national laboratories. At this point, it is believed that the fuel cell will be used in hybrid configuration rather than in a vehicle powered solely by fuel cells.

The fuel cell system will require a compact, lightweight, highly efficient air compressor/expander that will provide clean compressed air to the fuel cell stack. Turbocompressors are being developed to meet this requirement. Air bearings are preferred in the turbocompressor because bearing losses will be minimal, and the feed air will not be contaminated by oil. Under normal operation, a thin film of high-pressure air separates the load-bearing surfaces of an air bearing. However, during start and stop or system shock loading, the bearing surface will be in contact, resulting in frictional drag and wear.

Meruit, Inc., of Santa Monica, CA, has designed and built a journal radial and thrust air bearing for use in fuel cell turbocompressors [1]. Low friction and no wear are desirable when the bearing surfaces are in contact before gas dynamic lift, or during momentary transient overload. A solid lubricant that is well bonded to the bearing surface will be most suitable for this purpose.

Argonne recently developed a hard carbon-based coating with very low friction coefficients under dry sliding contact. This near-frictionless-carbon (NFC) coating also 
exhibits very good wear resistance. Friction coefficients as low as 0.002 and wear rates as low as $10^{-10} \mathrm{~mm}^{3} / \mathrm{Nm}$ have been measured with this coating in the laboratory under sliding contact in dry nitrogen [2,3]. The coating has potential for application in Meruit's radial journal and thrust bearings. This paper presents the laboratory benchtop tests comparing the performance of uncoated $440 \mathrm{C}$ stainless steel and NFC-coated surfaces using two parallel discs in sliding contact. This contact configuration is similar to that of the thrust bearings.

\section{EXPERIMENTAL DETAILS:}

\section{Coatings:}

The NFC coating was deposited on 50-mm-diameter hardened stainless steel disc test samples by an RF-plasma-assisted chemical vapor deposition (PACVD) method. The surfaces to be coated were first sputter-cleaned in Ar plasma for $30 \mathrm{~min}$. This was followed by a sputtering deposition of a 50-70-nm-thick Si bond layer. The sputtering cleaning and deposition of a Si bond layer were used to ensure good adhesion between the NFC coating and the substrate material. A proprietary mixture of gas was then blended into the chamber to create the plasma for chemical vapor deposition of the NFC coating. A coating of about $2 \mu \mathrm{m}$ thickness was deposited on disc surfaces to be tested.

\section{Wear Testing:}

Wear tests were conducted with hardened $\left(R_{c} 60\right) 440 \mathrm{C}$ stainless steel material with and without NFC coatings. The test specimens consisted of two 50-mm-diameter and 15mm-thick discs. A $1 \mathrm{~mm}$ recess was machined into the middle of one of the discs, as 
shown in Figure 1a. Prior to testing, dimples of known depth $(\approx 2 \mu \mathrm{m})$ and diameter $(0.5$ $\mathrm{mm}$ ) were created in the contact area of the disc with the recess.

During wear testing, one disc was held stationary while the other was rotated at a constant sliding speed and load, as shown schematically in Figure 1b. Because the contact between the bearing surfaces in the turbocompressor air bearing occurs just before gas dynamic lift, the contact load is relatively small. Tests were therefore conducted with a normal load of about $1.25 \mathrm{~N}$, speeds of 1000 and $500 \mathrm{rpm}$, and room temperature $\left(23^{\circ} \mathrm{C}\right)$ and relative humidity $(34-40 \%)$. Each was interrupted at a preset time interval to measure the change in dimension of the dimple. As the test progresses and wear occurs, the diameter of the dimples becomes smaller. Linear wear $\left(\mathrm{W}_{\mathrm{L}}\right)$ was then calculated from the dimensional change by:

$$
W_{L}=1 / 2\left\{\left[\sqrt{ }\left(4 R^{2}-d^{2}\right)\right]-\left[\sqrt{ }\left(4 R^{2}-D^{2}\right)\right]\right\}
$$

where $\mathrm{R}$ is the radius of curvature of dimple, $\mathrm{d}$ is dimple diameter after test, and $\mathrm{D}$ is initial dimple diameter. At the conclusion of the tests, wear surfaces were examined in a scanning electron microscope (SEM) to assess the mechanisms of wear and damage modes on both the coated and uncoated discs surfaces.

\section{RESULTS AND DISCUSSION:}

Significant differences were observed in the friction and wear behavior for the coated and uncoated surfaces. In general, the tests with uncoated specimens were relatively noisy, while the tests with coated specimens were relatively quiet. This, of course, is an indication of tribological phenomena occurring at the contact interface during testing. 
Figure 2 shows the average frictional force for NFC-coated and uncoated surfaces during tests at $1000 \mathrm{rpm}$. The NFC coating reduced the frictional force about four times. This friction reduction is needed by the turbocompressor air bearing for effective air dynamic lift-off. Recent air bearing test showed that high friction at the bearing surface could interfere with satisfactory air dynamic lift-off by causing scuffing damage or dynamic instability [4]. With a four fold reduction in friction by the NFC coating, a smooth air bearing lift is expected in NFC-coated bearings.

Average wear on coated and uncoated discs during the $1000 \mathrm{rpm}$ tests is shown in Figure 3. The NFC coating again reduced the linear wear rate by more than 100 times. Some of the dimples in the uncoated surfaces were worn through after 10 min of testing, whereas the coated tests ran for $100 \mathrm{~min}$ without wearing through any of the dimples. Only $50 \%$ of the coating thickness was worn. The variation of wear rate with time for coated surfaces, as shown in Figure 4, suggests that it will take a considerably longer time to wear through the remaining $50 \%$ of the NFC coating. Wear performance in the tests conducted at $500 \mathrm{rpm}$ was similar to those conducted at $1000 \mathrm{rpm}$. Figure 4 shows the average wear for coated and uncoated surfaces in the $500 \mathrm{rpm}$ tests. Again, wear was reduced by about 100 times with the NFC coating.

The good wear resistance of NFC coatings will also be very beneficial to air bearing durability and optimal performance. Recent air bearing tests [4] showed that radial air bearings are subject to wear when there is instability at the start of the tests. Wear increased the clearance between the shaft and journal in the radial bearing. The increased clearance will increase the dynamic instability in the bearing, causing even more wear. With the low wear ensured by the NFC coatings, the clearance between the shaft and the 
journal in the radial bearing can be maintained, thereby making the bearing dynamics more stable.

Figure 6 shows SEM micrographs of the 440C-uncoated disc before and after wear testing. Before testing, only a few scratches are visible on the polished disc surface (Figure 6a). After testing, the wear track was covered with debris (Figure 6b). EDAX analysis showed that the debris consisted primarily of iron oxide; this suggests an oxidative wear mechanism or post-wear oxidation of the debris. In any case, the presence of the relatively hard iron oxide at the contact interface is expected to produce more abrasive wear and perturb the interaction between contacting surfaces. This was most likely responsible for the noisy nature of the uncoated disc tests. Figure 7 shows the surfaces of the NFC-coated disc before and after wear tests. The wear mode on the coated surface was primarily polishing. There was very little evidence of wear debris accumulation. The resulting improvement in surface finish, plus the lack of debris accumulation, is expectẹd to result in lower friction and decreasing wear rates, as observed.

\section{SUMMARY:}

We used laboratory wear testing methods to evaluate Argonne's NFC coating for thrust air bearing application. With two hardened 440C steel disc in unidirectional sliding contact, the NFC coating reduced the frictional force by about four times and the linear wear rate by more than 100 times. These results show that the NFC coating is a very good candidate for use in fuel cell turbo-compressor air bearings, where both low friction and low wear are required. Wear on uncoated surfaces involved oxidation 
generating hard iron oxide debris, while the wear mode on the NFC-coated surface consisted only of polishing.

\section{REFERENCES:}

1. G. Fonda-Bonardi, "Gas Bearing for High-Speed Turbomachinery", Paper presented at July 1998 ASME Fluids Engineering Conference, Washington, DC. (FEDSM985120).

2. A. Erdemir, G. R. Fenske, J. Terry, and P. Wilbur, "Effect of Source Gas and Deposition Method on Friction and Wear Performance of Diamondlike carbon Films", Surface and Coatings Technology, 94-95 (1997) 525-530.

3. J. DeGaspari, "Super-Slick", Mechanical Engineering, Vol. 121/No. 4 (1999) 4648.

4. G. Fonda-Bonardi "Electrically Boosted Gas Bearing Turbocompressor", Report DOE PRDA DE-FC02-97EE-50480, June 15, 1999.

\section{ACKNOWLEDGMENT:}

This work was supported by the U.S. Department of Energy, Office of Transportation Technology.

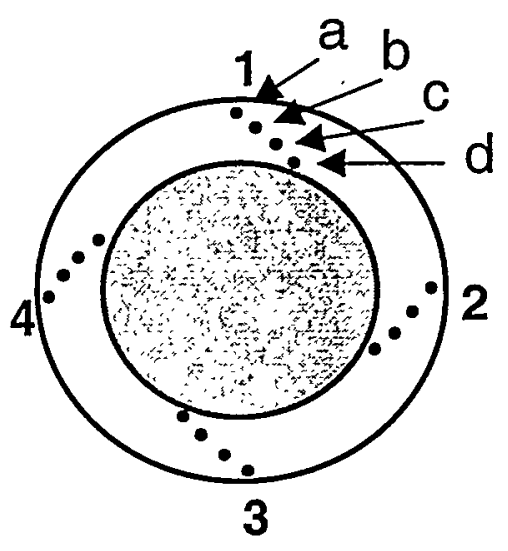

(a)

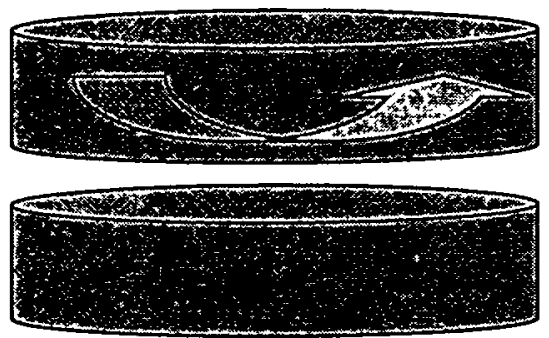

(b)

Figure 1: Schematic Diagram of Thrust Washer Test Configuration. 
Figure 2: Relative Frictional Force on NFC-Coated \& Uncoated Steel Surfaces

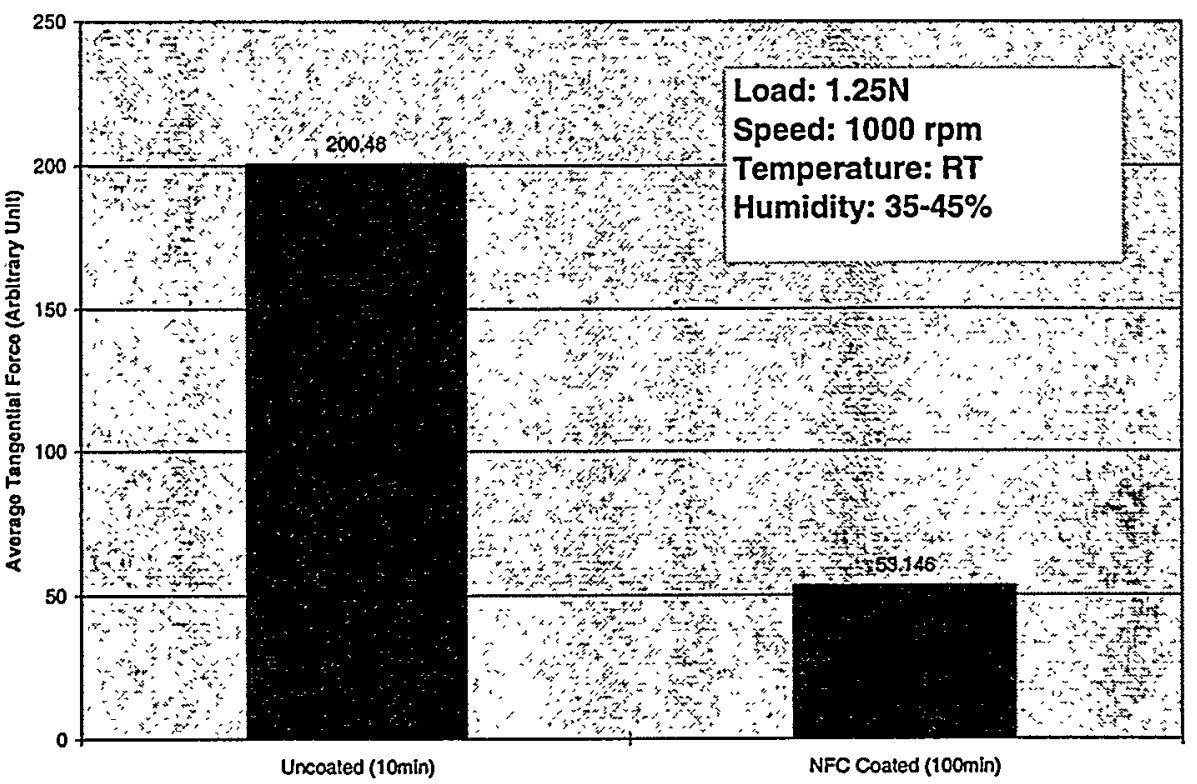

Figure 3: Average Linear Wear Rate on NFC-Coated and Uncoated Surfaces

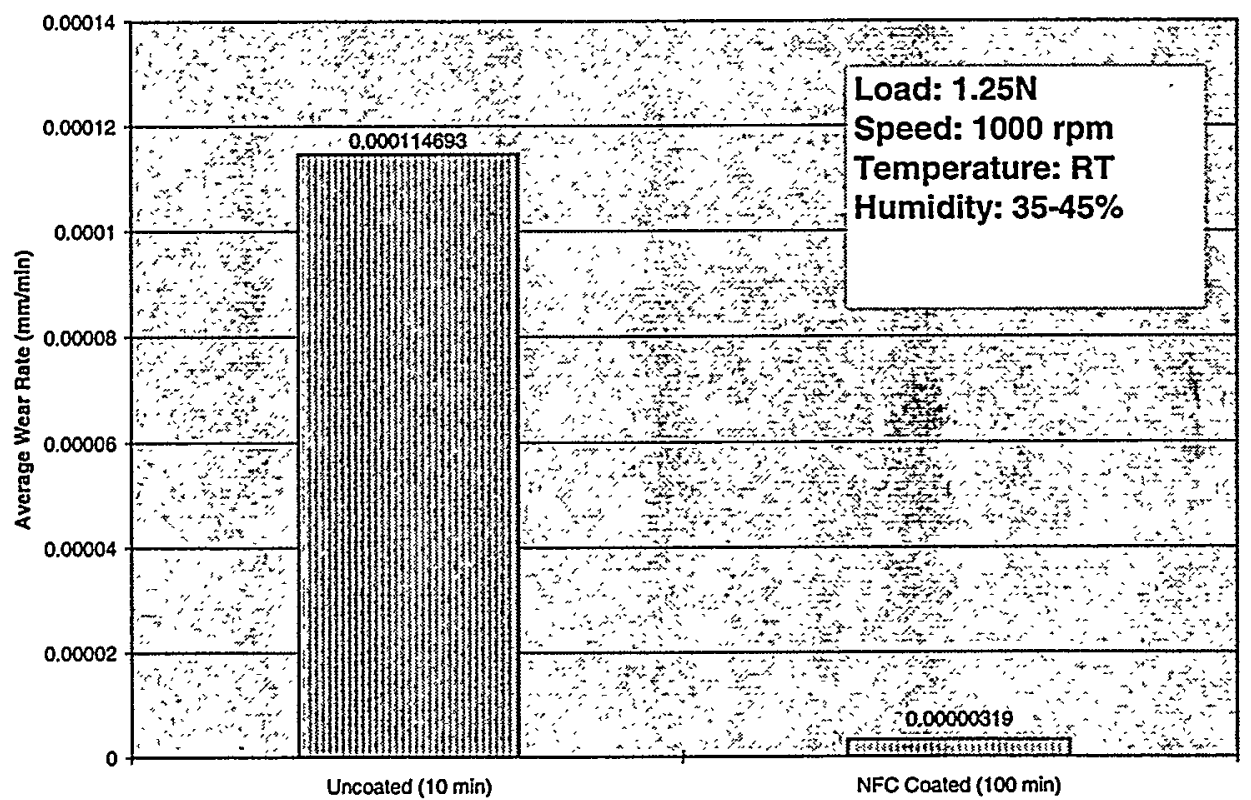


Figure 4: Variation of Average Linear Wear Rate on NFC-Coated Surface with Time

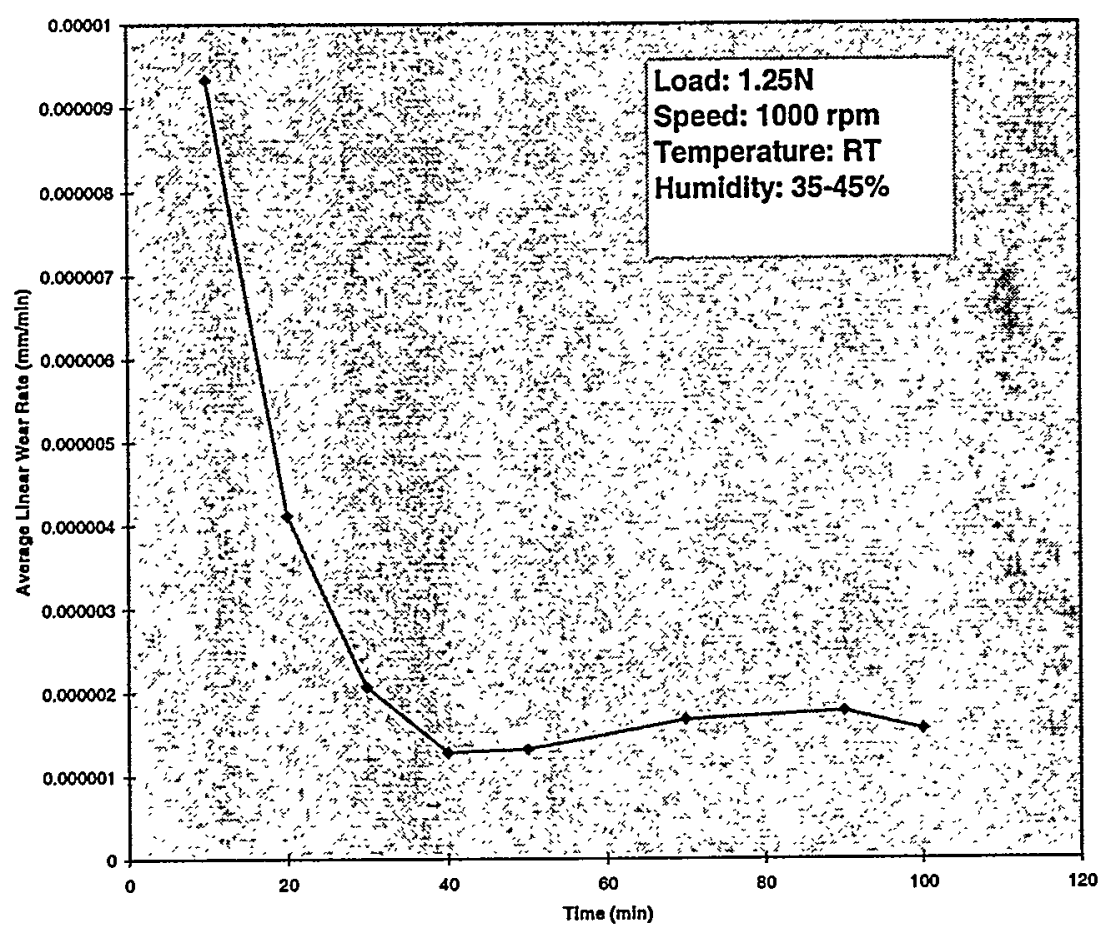

Figure 5: Average Linear Wear Rate on NFC Coated and Uncoated Surfaces

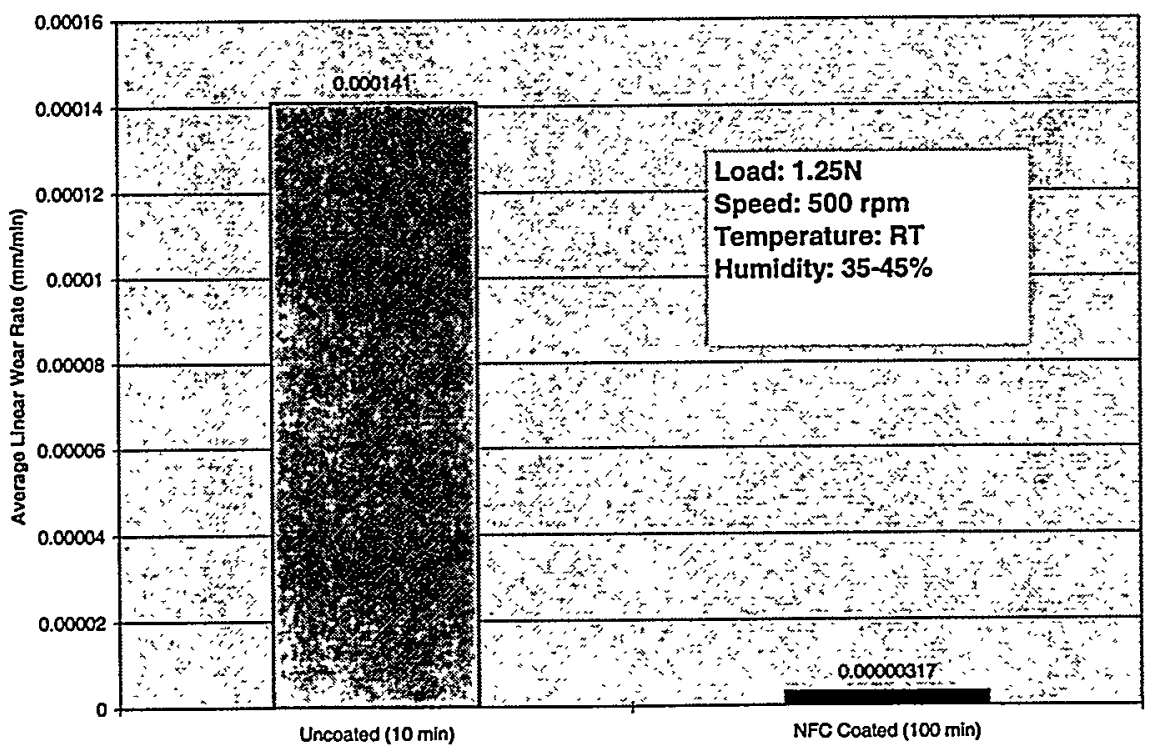




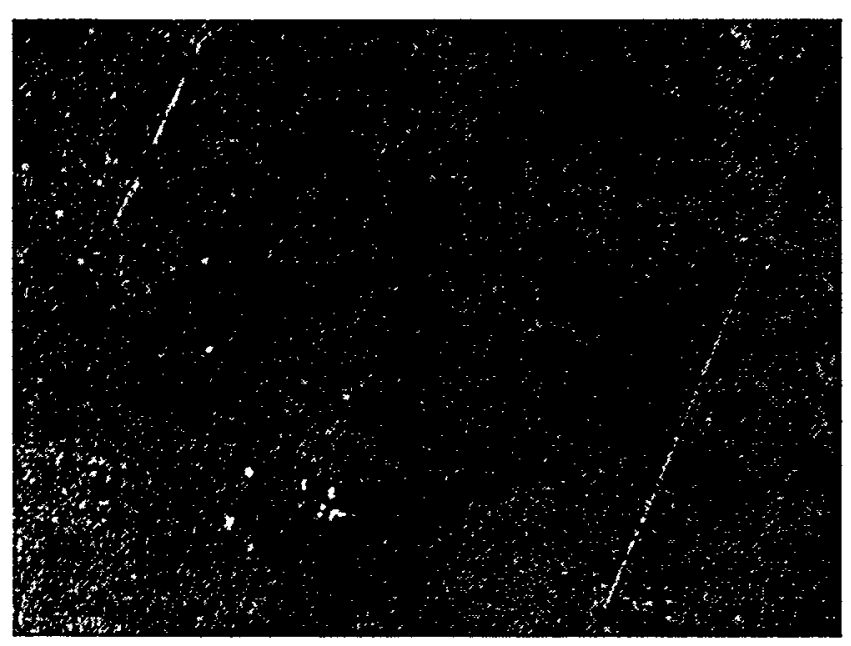

(a) Unworn surface

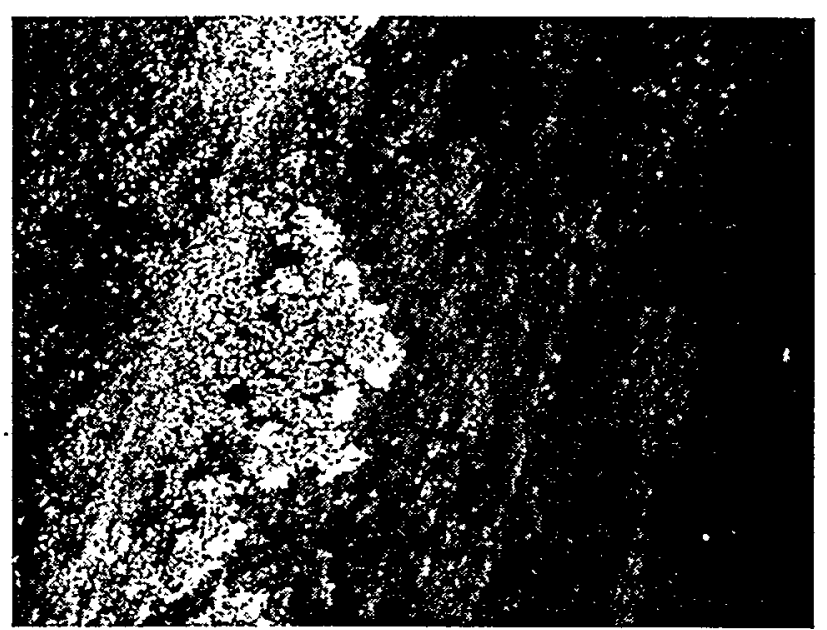

(b) Worn surface with debris

Figure 6: SEM Micrograph of Uncoated Steel Surface before and after Wear Testing.

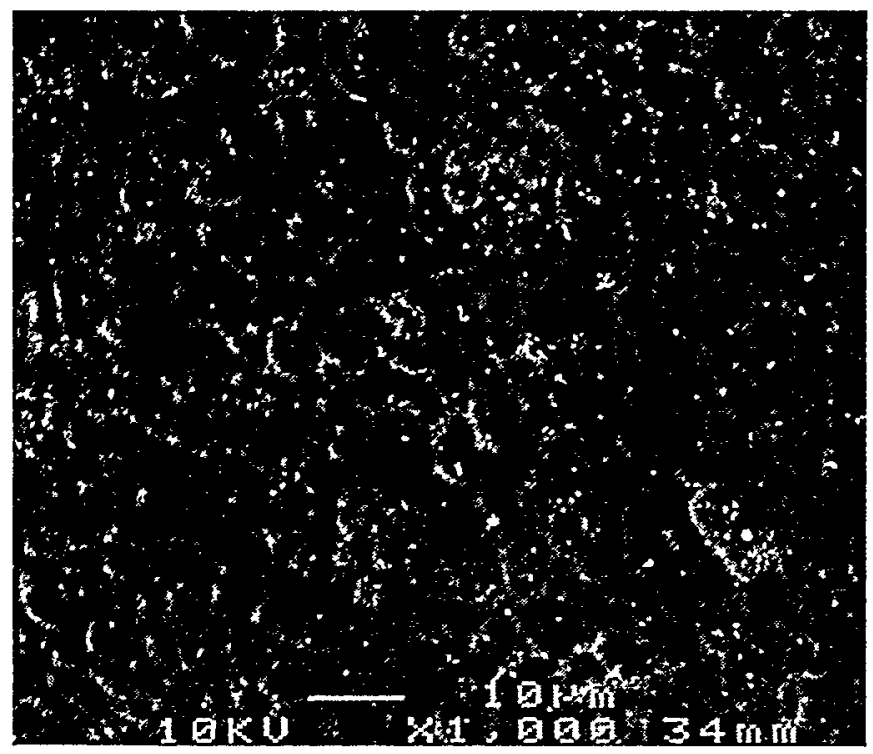

(a) Unworn surface

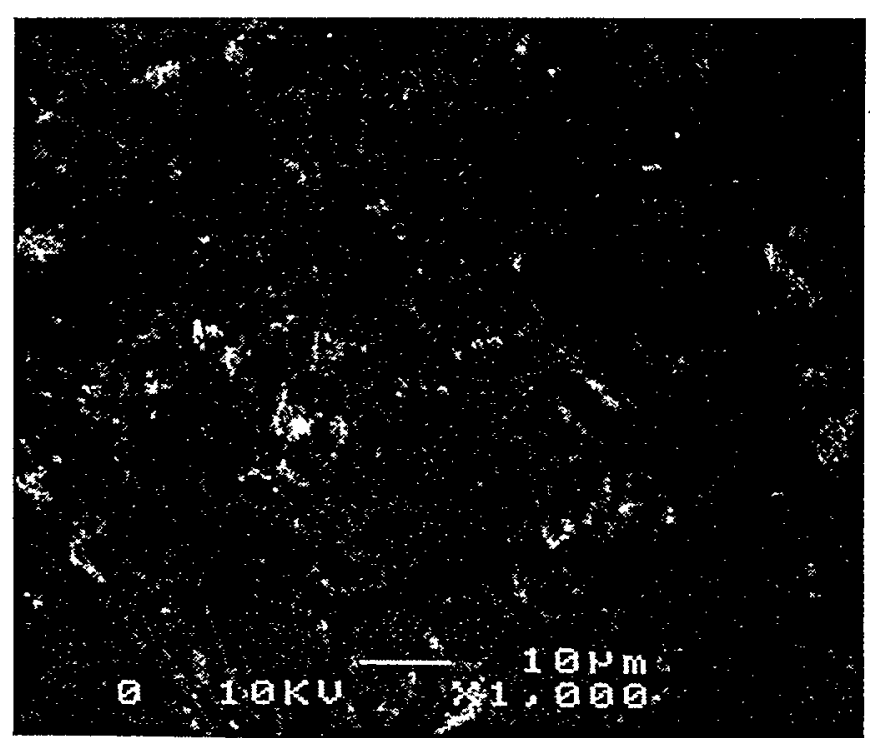

(b) Worn surface with no debris

Figure 7: SEM Micrograph of Uncoated Steel Surface before and after Wear Testing. 